\title{
Alternatif Rancangan Alat Panggang Kue Balok Ramah Lingkungan Menggunakan Liquefied Petroleum Gas (LPG)
}

\author{
Dwi Novirani, Hari Adianto, Ricky Januar E \\ Jurusan Teknik Industri, Institut Teknologi Nasional (Itenas) Bandung \\ Email: dwinovirani@gmail.com
}

\begin{abstract}
ABSTRAK
Perancangan alat panggang Kue Balok ramah lingkungan berbahan bakar gas, perlu dilakukan karena penjual Kue Balok di Kota Bandung masih menggunakan alat panggang dengan bahan bakar arang, yang mempunyai kekurangan seperti pembakaran awal yang membutuhkan waktu lama, sisa pembakaran arang seperti asap dan debu yang menggandung karsinogen, yang buruk untuk kesehatan, sehingga kekurangan tersebut harus dihilangkan supaya lebih bersih aman dan nyaman, dan diharapkan dapat digunakan di restoran, mall dan acara pernikahan. Alternatif perancangan ini menggunakan metode VDI 2222.
\end{abstract}

Kata kunci: Perancangan, Alat Panggang, Kue Balok, Gas, ramah lingkungan.

\begin{abstract}
The design of green Kue Balok baking equipment fueled by gas needs to be made because the cake seller in Bandung still uses the baking tools with fueled by charcoal, which has shortcomings such as charcoal burning which takes a long time, charcoal residue such as smoke and dust which contain carcinogen materials, which is bad for health, so it must be eliminated in order to make it more secure and comfortable, and is expected to be used in restaurants, malls and weddings. This designing alternative uses the VDI 2222 method.
\end{abstract}

Keywords: Design, Baking Equipment, Kue Balok, Gas, Green 


\section{PENDAHULUAN}

Pedagang Kue Balok di Kota Bandung masih menggunakan alat sederhana yang menggunakan bahan bakar arang, dengan menggunakan perancangan menurut Ulrich et al., 2001 [1] maka dirancang alat panggang Kue Balok oleh Liansari et al., 2016 [2] yang menghasilkan sebuah rancangan Blue Print yang Ergonomis menurut Damayanti et al., 2000 [3]

Alat panggang tersebut kemudian dibuat prototypenya oleh Novirani et al., 2016 [4] yang portable dan dilakukan uji fungsi dengan melihat proses disain mekanik menurut Ulman et al., 2010 [5] dan Budynas et al.,2006 [6] yang berguna untuk penyempurnaan rancangan awal, kemudian dilakukan beberapa perubahan pada alat panggang tersebut, antara lain pada tempat arang bagian atas di buatkan Tray supaya dapat diangkat dan dipindahkan dengan mudah menurut Khurmi et al., 2005 [7] saat proses penyalaan arang serta mempercepat penyalaan awal bara api, namun masih memiliki kendala seperti penyalaan arang yang memerlukan waktu cukup lama dan menghasilkan abu dari arang yang mengandung karsinogen yang berbahaya bagi kesehatan, yang kadangkala abu tersebut bercampur dengan adonan Kue Balok yang juga beresiko kanker menurut Lawrence et al., 2012 [8]
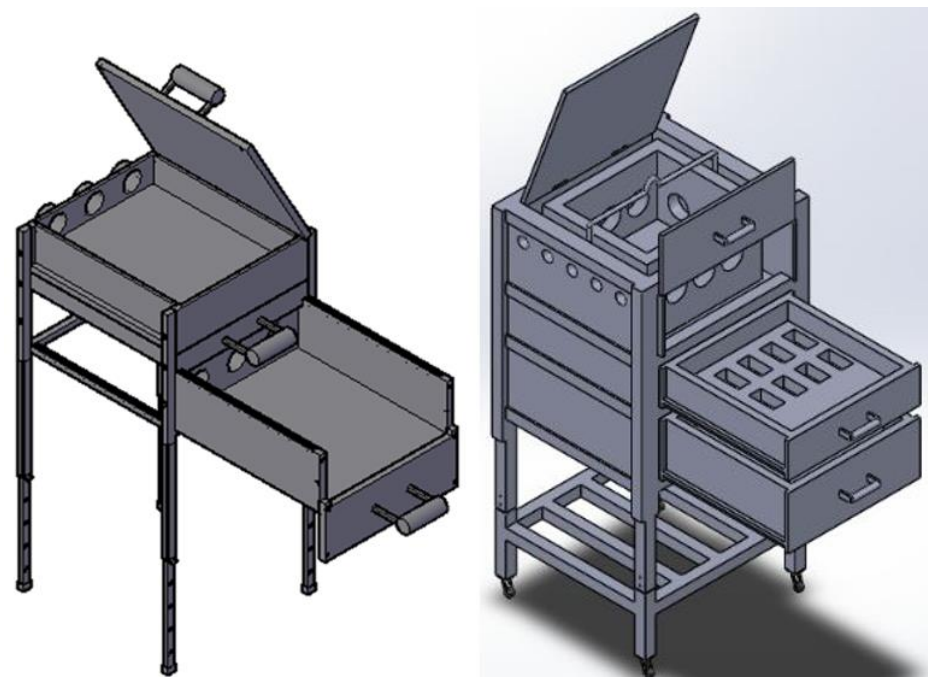

Gambar 1. Prototype alat panggang Kue Balok bahan bakar Arang

Kekurangan dari alat panggang tersebut sebaiknya ditiadakan supaya lebih nyaman, bersih dan aman, sehingga dilakukan perancangan beberapa alternative alat panggangan Kue Balok yang berbahan bakar Liquefied Petroleum Gas (LPG), untuk menggantikan proses pembakaran dengan arang, yang tidak menimbulkan sisa pembakaran berupa asap dan debu arang, sehingga lebih mudah pengoperasiaannya serta lebih higienis dan dapat dipergunakan di restoran, ditempat perkawinan serta di Mall.

\section{STUDI LITERATUR}

\subsection{Metode Perancangan}

Perancangan menurut Pahl et al., 2010 [9] adalah proses yang dilakukan architects, engineers, industrials designers dan bidang keilmuan lain lakukan untuk menghasilkan gambaran yang dibutuhkan oleh clients/ konsumen maupun manufaktur. Metode perancangan yang diterapkan mengacu pada metode tahapan perancangan menurut VDI 2222 (Verein Deutsche Inginieuer 2222), merupakan metode perancangan sistematik terhadap desain untuk merumuskan dan mengarahkan 
berbagai macam metode desain yang makin berkembang akibat kegiatan riset. Tahap-tahap perancangan yang dilakukan bisa dilihat pada Gambar 2 .

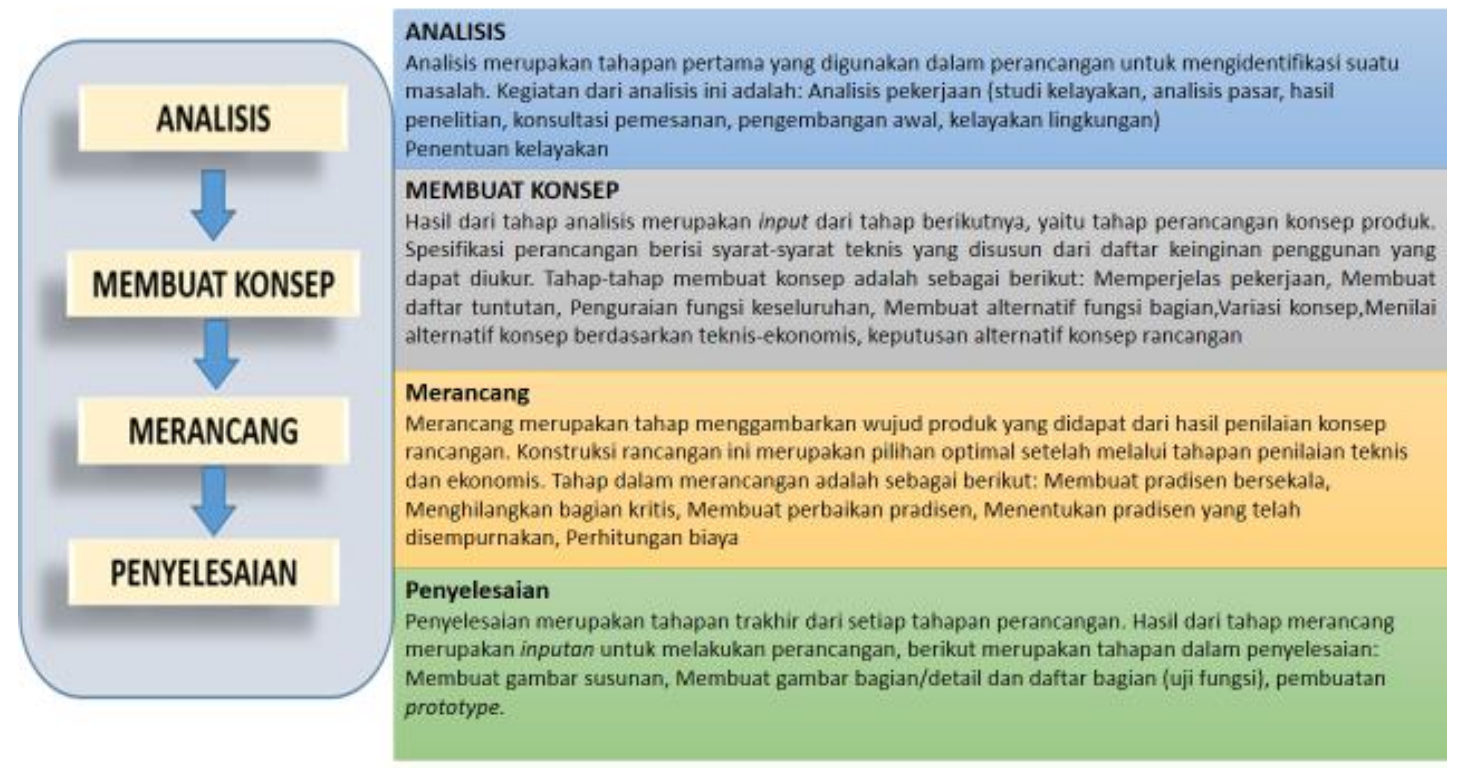

Gambar 2 Tahap-tahap perancangan yang dilakukan metode VDI 2222

\subsection{Pemanggang Gas}

Pemanggang gas mempunyai system seperti kompor gas yang merupakan alat penghasil api digunakan untuk memanaskan suatu benda dengan menggunakan bahan bakar gas alam cair yang telah dikemas dalam tabung. Kompor gas sendiri memiliki cara kerja gas masuk kedalam saluran ketika katup dibuka, katup dapat dibuka dengan $O N / O F F$ yang dapat disesuaikan alirannnya.

\section{PEMBAHASAN}

\subsection{Pembuatan Konsep Perancangan Alat Panggang LPG}

Konsep yang digunakan dalam usulan perancangan alat panggang Kue Balok bahan bakar gas melalui tahapan-tahapan pembuatan konsep metode VDI 2222 yang digunakan untuk memperjelas pekerjaan serta dibuat daftar tuntutan, dengan tujuan perancangan yang ingin dicapai, menghasilkan desain usulan alat panggang Kue Balok

Secara garis besar menurut Monica et al., 2016 [10] yang harus dipenuhi dalam perancangan adalah pengoperasian praktis, ringan, dimensi proporsional, mudah perawatan, aman, dan harga bersaing. Dalam daftar tuntutan terdapat perancangan alat panggang Kue Balok dan material yang digunakan.

1. Perancangan Alat Panggang Kue Balok

Pembuatan rancangan alat panggang Kue Balok ini bertujuan agar semakin meluasnya target penjualan kuliner khas tradisional. Alat yang sekarang memiliki kekurangan seperti sisa hasil pembakaran berupa asap yang mengganggu, debu sisa pembakaran arang, waktu yang cukup lama untuk menghasilkan Kue Balok.

2. Material Alat Panggang Kue Balok

Material harus sesuai, Callister et al., 2010 [11] dan Craig et al., 2011 [12] khususnya untuk alat panggang Kue Balok perlu ditentukan agar operator dapat menggunakan alat dengan aman dan alat dapat diproduksi dan memerlukan waktu yang singkat dengan biaya seminim mungkin. 


\subsection{Tahap Perancangan Alat Panggang Kue Balok LPG}

Sub bab perancangan ini terdiri dari penentuan ukuran rancangan serta perancangan alat panggang Kue Balok beserta penentuan material yang digunakan. Rancangan menggunakan ukuran prototype yang di buat Novirani et al., 2016 [4] dan perancangan menggunakan tool matriks morfologi agar dapat membuat alternatif rancangan.

\section{Penentuan Ukuran Rancangan}

Ukuran rancangan yang digunakan sesuai dengan prototype alat panggang Kue Balok yang di buat oleh Novirani et al., 2016 [4] memfokuskan hanya pada 3 dimensi saja agar tidak mengurangi ENASE dari prototype alat panggang kue balok, yaitu lebih ringan, dimensi lebar dan panjang yang dikurangi namun tidak mengurangi ENASE, meminimasi dimensi berarti meminimasi biaya produksi dikarenakan pengurangan penggunaan bahan. Alat yang dirancang menurut Harsokoesoemo et al., 2004 [13] akan lebih baik apabila lebih ringan, dimensi proporsional, mudah perawatan, aman, dan harga bersaing. Ditentukan perancangan dengan dimensi seperti pada tabel 1:

Tabel 1. Dimensi Alat Panggang Kue Balok

\begin{tabular}{clc}
\hline No & \multicolumn{1}{c}{ Dimensi } & Spesifikasi $(\mathbf{c m})$ \\
\hline 1 & Panjang wadah bahan bakar & 46 \\
\hline 2 & Lebar wadah bahan bakar & 43 \\
\hline 3 & Tinggi wadah bahan bakar & 20 \\
\hline 4 & Panjang cetakan & 40 \\
\hline 5 & Lebar cetakan & 37 \\
\hline 6 & Tinggi cetakan & 10 \\
\hline 7 & Panjang penutup & 40 \\
\hline 8 & Lebar penutup & 37 \\
\hline 9 & Tinggi meja & 92 \\
\hline 10 & Panjang meja & 46 \\
\hline 11 & Lebar meja & 43 \\
\hline 12 & Tinggi penutup & 20 \\
\hline 13 & Diameter pengalih hawa panas dan asap & - \\
\hline
\end{tabular}

\section{Perancangan Alat Panggang Kue Balok LPG}

Secara garis besar rancangan alat panggang terdiri dari cetakan, rangka, ruang bakar atas, ruang bakar bawah. Perancangan dipermudah dengan membuat Matriks Morfologi alat panggang Kue Balok pada Tabel 2. yang mengahasilkan rancangan alternatif, namun untuk mengoptimalkan alat maka dilakukan pengurangan pilihan komponen penyusun.

Rancangan rangka untuk model persegi pejal dan silinder pejal tidak dijadikan alternatif karena tidak sesuai dengan daftar tuntutan alat yaitu untuk menghasilkan alat yang ringan dan harga bersaing. Material persegi dan silinder pejal akan membuat alat lebih berat dan memiliki harga yang relatif lebih mahal dibanding dengan bahan hollow.

Rancangan material menurut Ashby et al., 2007 [14] dapat menggunakan allumunium maupun stainless steel 304, dan tidak berkorosi menurut Askeland et al., 2010 [15] yang digunakan untuk dinding permukaan alat panggang Kue Balok, penggunaan material kayu dan iron dihilangkan karena tidak memenuhi daftar tuntutan keamanan. Perancangan difokuskan dengan menggunakan stainless steel karena memenuhi standard food grade. 
Tabel 2. Matriks Morfologi Alat Panggang Kue Balok

\begin{tabular}{|c|c|c|}
\hline \multicolumn{3}{|c|}{ Rangka } \\
\hline \multirow{3}{*}{ Material (A) } & Stainless Steel & A4. 201 \\
\hline & Stainless Steel & A5. 304 \\
\hline & Stainless Steel & A6. 316 \\
\hline \multirow{2}{*}{ Model (B) } & Kotak & B2. Hollow \\
\hline & Silinder & B4. Hollow \\
\hline \multicolumn{3}{|c|}{ Dinding } \\
\hline \multirow{3}{*}{ Material (C) } & Stainless Steel & C4. 201 \\
\hline & Stainless Steel & C5. 304 \\
\hline & Stainless Steel & C6. 316 \\
\hline \multicolumn{3}{|c|}{ Cetakan } \\
\hline \multirow{3}{*}{ Material (D) } & Stainless Steel & D4. 201 \\
\hline & Stainless Steel & D5. 304 \\
\hline & Stainless Steel & D6. 316 \\
\hline \multicolumn{2}{|c|}{ Production Rate $(\mathrm{E})$} & E1. 10 Buah \\
\hline \multicolumn{3}{|c|}{ Ruang Bakar } \\
\hline \multicolumn{2}{|c|}{ Jumlah Tungku (F) } & F2. 2 (Dua) Tungku \\
\hline \multirow{2}{*}{\multicolumn{2}{|c|}{ Jenis Tungku $(\mathrm{G})$}} & G1. Kompor Mawar/bulat \\
\hline & & G2. Silinder \\
\hline
\end{tabular}

Rancangan untuk tungku api yang berada didalam ruang bakar menggunakan tungku model tabung dan bulat. Tungu api mengaplikasikan model yang tersedia di penjualan komponen kompor, sehingga pembuatan alat panggang kue balok tidak melakukan casting tersendiri untuk model tungku. Jumlah tungku memungkinkan diaplikasikan berjumlah satu atau dua tungku.

Semua alternative menggunakan jalur pipa yang diaplikasikan agar dapat menggunakan satu buah tabung gas, berukuran setengah inchi sesuai pipa yang banyak disediakan supplier untuk bahan perakitan kompor gas. Proses pembuatan jalur dengan pipa berbahan cooper/tembaga dengan proses assembly dan wielding pada beberapa bagiannya. Dirancang agar hanya memerlukan satu tabung gas berukuran kecil yang dapat diletakkan pada bagian bawah agar menghemat ruang dan mudah untuk pengoperasiannya apa bila gas habis atau perlu di lepaskan. Tabung gas yang direkomendasikan adalah tabung gas $3 \mathrm{~kg}$ karena menyesuaikan ruang yang ada pada alat panggang. Regulator adalah jenis regulator yang biasa dan umum yang digunakan pada alat panggang Kue Balok ini, dan menggunakan roda pada kakinya agar mudah dipindahkan serta kakinya dapat dinaik turunkan.

Alternatif yang beragam dapat dihasilkan untuk menghasilkan alat panggang Kue Balok yang berbahan bakar LPG, untuk itu dilakukan pengurangan pilihan sesuai kriteria, sehingga dapat terfokus pada alternatif yang terbaik. Hasil diskusi dengan para pemakai alat Kue Balok didapatkan tiga kombinasi rancangan konsep yang mengacu pada tabel 2 Matriks morfologi alat panggang Kue Balok yaitu

Rancangan 1 = A4 + B2 + C4 + D5 + E1 + F2 + G2, Rancangan $2=\mathrm{A} 6+\mathrm{B} 4+\mathrm{C} 6+\mathrm{D} 5+\mathrm{E} 1+\mathrm{F} 2+$ $\mathrm{G} 1$, dan Rancangan $3=\mathrm{A} 5+\mathrm{B} 2+\mathrm{C} 5+\mathrm{D} 5+\mathrm{E} 1+\mathrm{F} 2+\mathrm{G} 1$, dengan gambar teknik yang menggunakan AutoCAD 2011, Omura 2010 [16] 


\section{A. Rancangan 1}

Pengembangan konsep produk menggunakan gabungan dimensi $\mathrm{A} 4+\mathrm{B} 2+\mathrm{C} 4+\mathrm{D} 5+\mathrm{E} 1+\mathrm{F} 2+\mathrm{G} 2$ dengan pada Gambar 3 dan Tabel 3 Bill Of Material Table dan keterangan bahan yang merupakan rancangan 1 yang memiliki dua tungku dengan bentuk silinder, sudah dapat memenuhi syarat dengan memasak Kue Balok dengan lebih cepat dibandingkan menggunakan satu tungku. Tungku bakar menggunakan model silinder yang juga terdapat pada supplier komponen kompor, sehingga dapat memperkecil biaya, Ada empat roda untuk mempermudah pergerakan dan memiliki frame silinder pada setiap bagiannya. Dirancang agar hanya memerlukan satu tabung gas.

Tabel 3. Bill Of Material Table Rancangan 1

\begin{tabular}{cccc}
\hline \multicolumn{4}{c}{ BOM TABLE } \\
\hline ITEM NO. & PART & DESCRIPTION & QTY. \\
\hline \hline 1 & Frame & Stainless Steel & 1 \\
\hline 2 & Top Cover & Stainless Steel & 1 \\
\hline 3 & Coal Drawer & Stainless Steel & 1 \\
\hline 4 & Side Cover & Stainless Steel & 1 \\
\hline 5 & Furnace & Alumunium & 4 \\
\hline 6 & Main Gas Pipe & Copper & 2 \\
\hline 7 & Pipe to Gas & Copper & 1 \\
\hline 8 & Regulator & Brass & 1 \\
\hline 9 & T Pipe & Copper & 1 \\
\hline 10 & Hose & Rubber & 1 \\
\hline 11 & Caster Wheel & Rubber & 4 \\
\hline 12 & LPG case & Iron & 1 \\
\hline
\end{tabular}

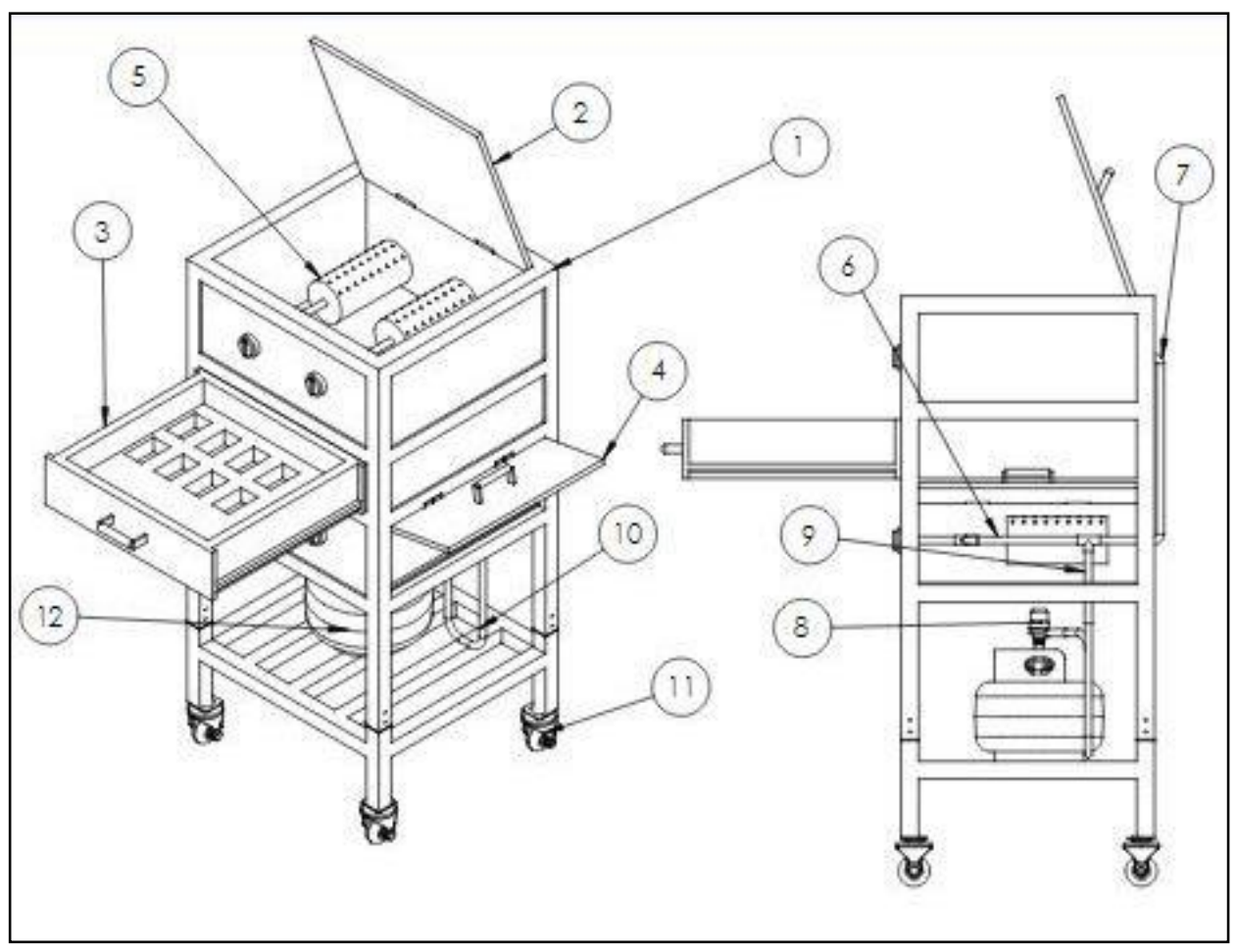

Gambar 3. Alat Panggang Kue Balok Rancangan 1 


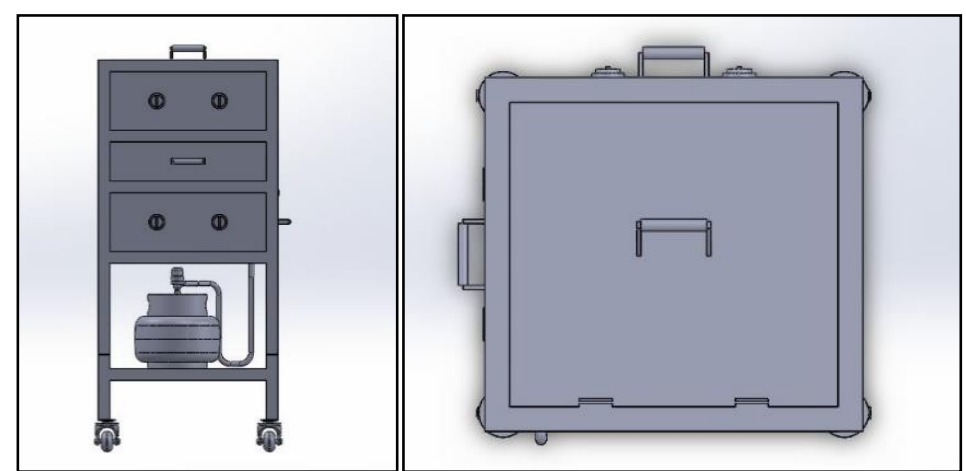

Gambar 4.Alat Panggang Kue Balok Rancangan 1 Tampak Depan dan Tampak Atas

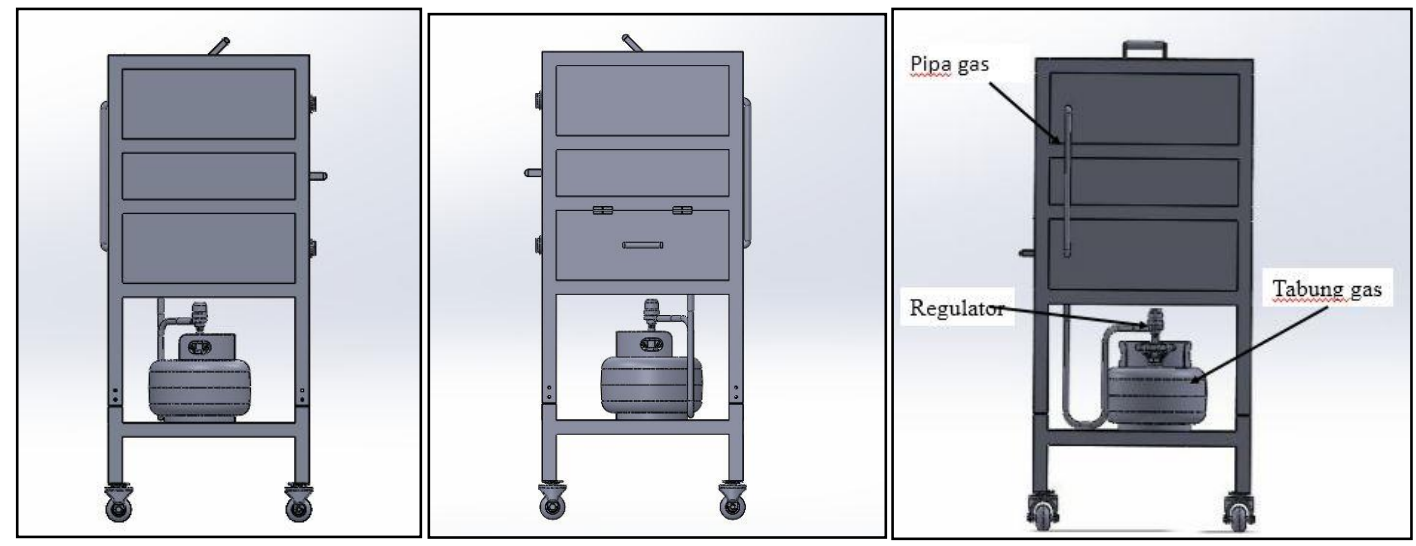

Gambar 5 Alat Panggang Kue Balok Rancangan 1 Tampak Samping Kiri, Samping Kanan dan Belakang

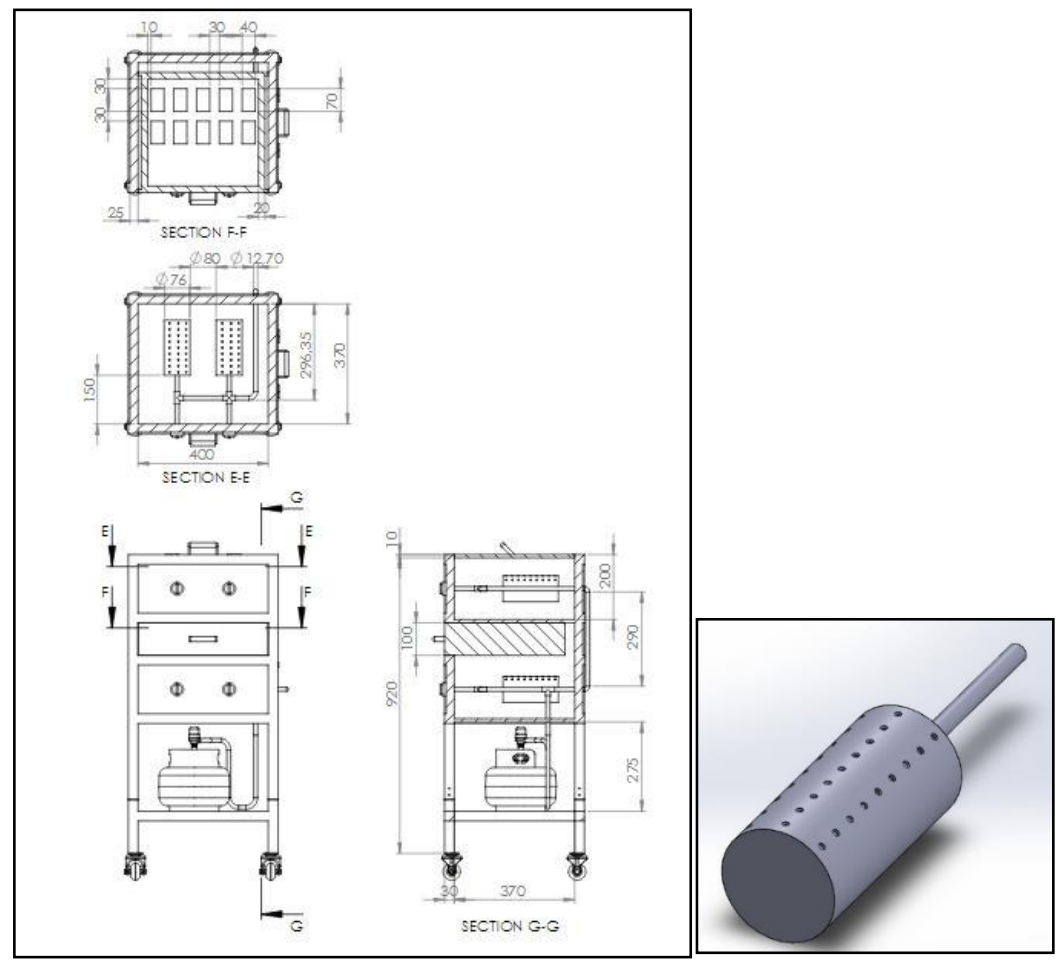

Gambar 6. Alat Panggang Kue Balok Rancangan 1 Tungku Silinder Jurnal Rekayasa Hijau - 202 


\section{B. Rancangan 2}

Pengembangan konsep produk menggunakan gabungan dimensi A6 + B4 + C6 + D5 + E1 + F2 + G1 merupakan rancangan Produk 2 memiliki dua tungku, diharapkan lebih cepat dibandingkan menggunakan satu tungku, digunakan model bulat yang ada di pasaran untuk minimasi biaya

Ada roda untuk moveable. Rancangan ini memiliki frame silinder pada setiap bagiannya. Dirancang agar hanya memerlukan satu tabung gas.terdapat pada Gambar 7 dan Tabel 4 Bill Of Material Table beserta keterangan bahan.

Tabel 4. Bill Of Material Table Rancangan 2

\begin{tabular}{cccc}
\hline \multicolumn{5}{c}{ BOM TABLE } \\
\hline ITEM NO. & PART & DESCRIPTION & QTY. \\
\hline \hline 1 & Frame Pipa & Stainless Steel & 1 \\
\hline 2 & Top Cover & Stainless Steel & 1 \\
\hline 3 & Coal Drawer & Stainless Steel & 1 \\
\hline 4 & Side Cover & Stainless Steel & 1 \\
\hline 5 & Main Gas Pipe & Copper & 2 \\
\hline 6 & Pipe to Gas & Copper & 1 \\
\hline 7 & Regulator & Brass & 1 \\
\hline 8 & T Pipe & Copper & 1 \\
\hline 9 & Hose & Rubber & 1 \\
\hline 10 & Caster Wheel & Rubber & 4 \\
\hline 11 & LPG case & Iron & 1 \\
\hline 12 & Pemantik & Iron & 4 \\
\hline 13 & Ujung Saluran Gas & iron & 4 \\
\hline 14 & Burner & 4 \\
\hline
\end{tabular}

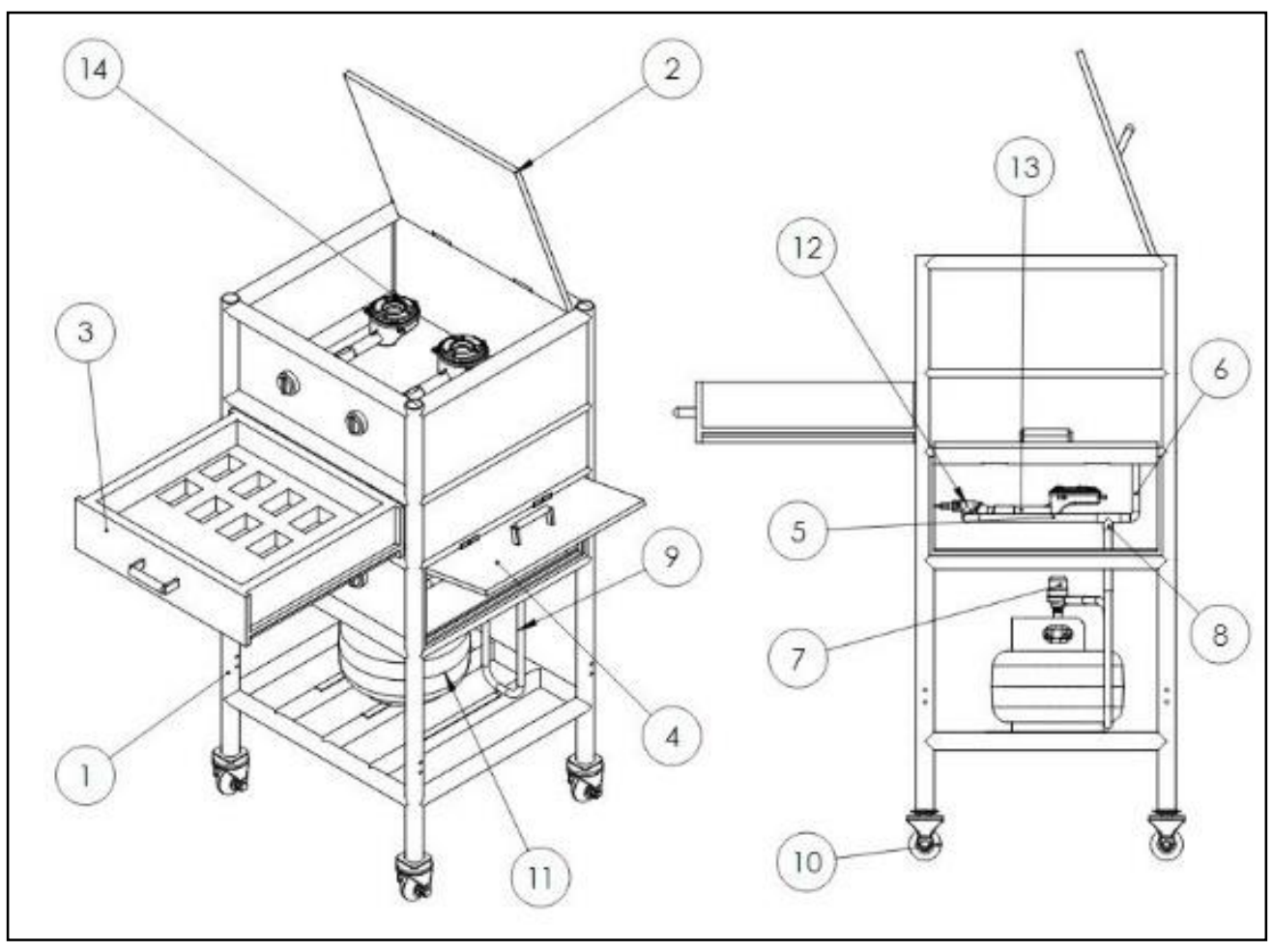

Gambar 7. Alat Panggang Kue Balok Rancangan 2 


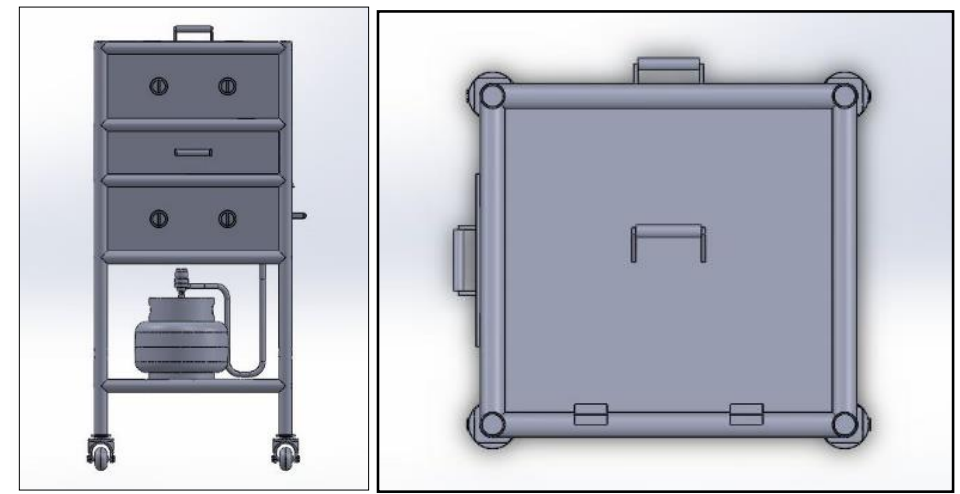

Gambar 8. Alat Panggang Kue Balok Rancangan 2 Tampak Depan dan Tampak Atas

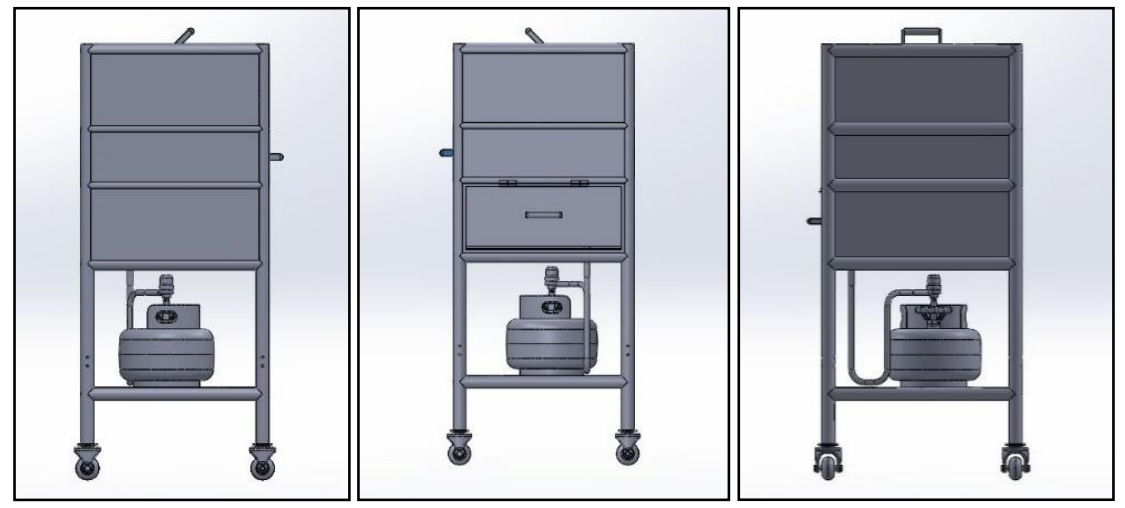

Gambar 9. Alat Panggang Kue Balok Rancangan 2 Tampak Samping Kiri , Tampak Samping Kanan dan Tampak Belakang

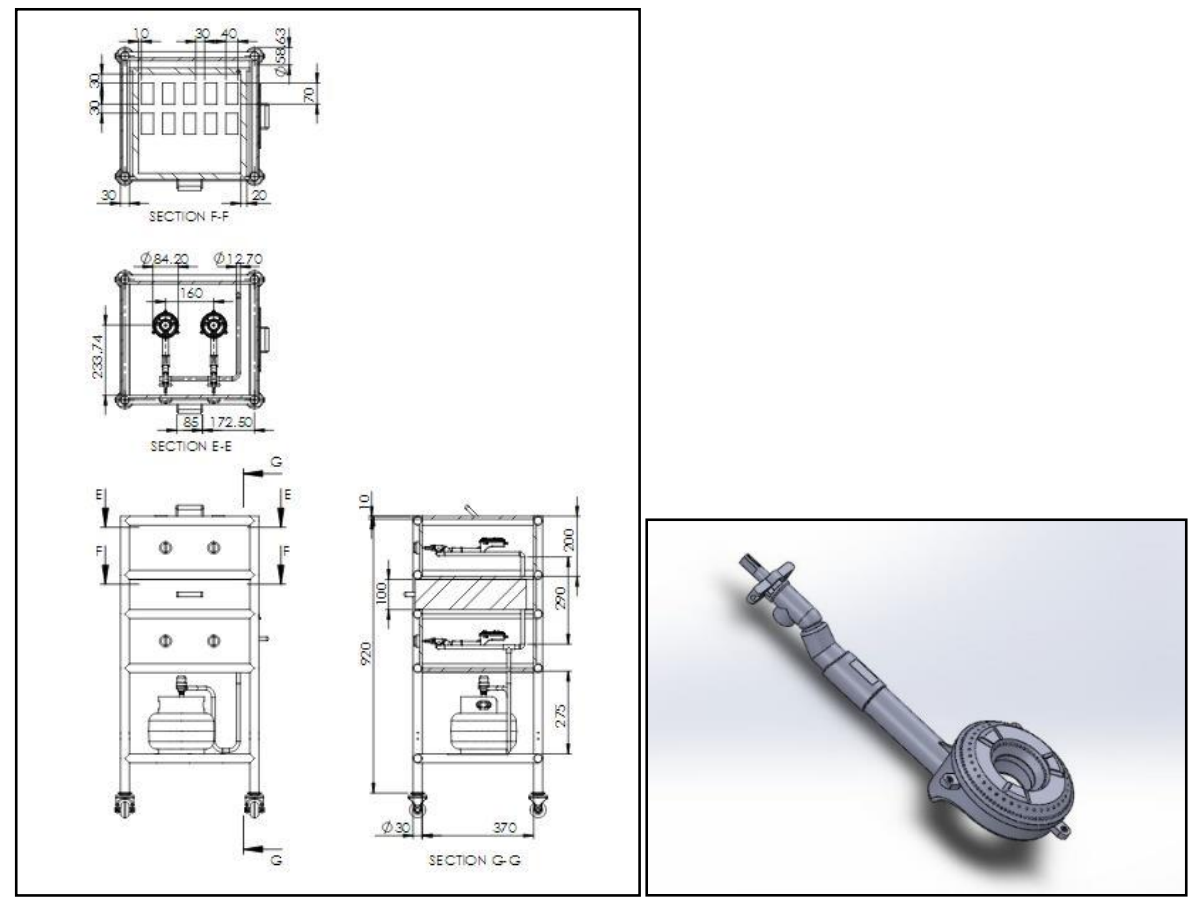

Gambar 10. Alat Panggang Kue Balok Rancangan 2 dan Tungku Bulat 


\section{Rancangan 3}

Pengembangan konsep produk menggunakan gabungan dimensi A5 + B2 + C5 + D5 + E1 + F2 + G1 rancangan 3 memiliki 2 tungku berbentuk bulat. Rancangan ini memiliki frame persegi pada setiap bagiannya. Ada roda untuk moveable. Rancangan ini memiliki frame silinder pada setiap bagiannya. Dirancang agar hanya memerlukan satu tabung gas. Tabung gas diletakan pada sebuah laci dibagian bawah alat panggang, sehingga terlihat lebih rapih.pada Gambar 11 dan Tabel 5 Bill Of Material Table.

Tabel 5 Bill Of Material Table Rancangan 3

\begin{tabular}{cccc}
\hline \multicolumn{5}{c}{ BOM TABLE } \\
\hline ITEM NO. & PART & DESCRIPTION & QTY. \\
\hline \hline 1 & Frame Pipa & Stainless Steel & 1 \\
\hline 2 & Top Cover & Stainless Steel & 1 \\
\hline 3 & Coal Drawer & Stainless Steel & 1 \\
\hline 4 & Side Cover & Stainless Steel & 1 \\
\hline 5 & Main Gas Pipe & Copper & 2 \\
\hline 6 & Pipe to Gas & Copper & 1 \\
\hline 7 & Regulator & Brass & 1 \\
\hline 8 & T Pipe & Copper & 1 \\
\hline 9 & Hose & Rubber & 1 \\
\hline 10 & Caster Wheel & Plastic & 4 \\
\hline 11 & LPG case & Iron & 1 \\
\hline 12 & Pemantik & Alumunium & 4 \\
\hline 13 & Ujung Saluran Gas & iron & 4 \\
\hline 14 & Burner & Stainless Steel \\
\hline 15 & Pintu Depan Laci & & \\
\hline
\end{tabular}

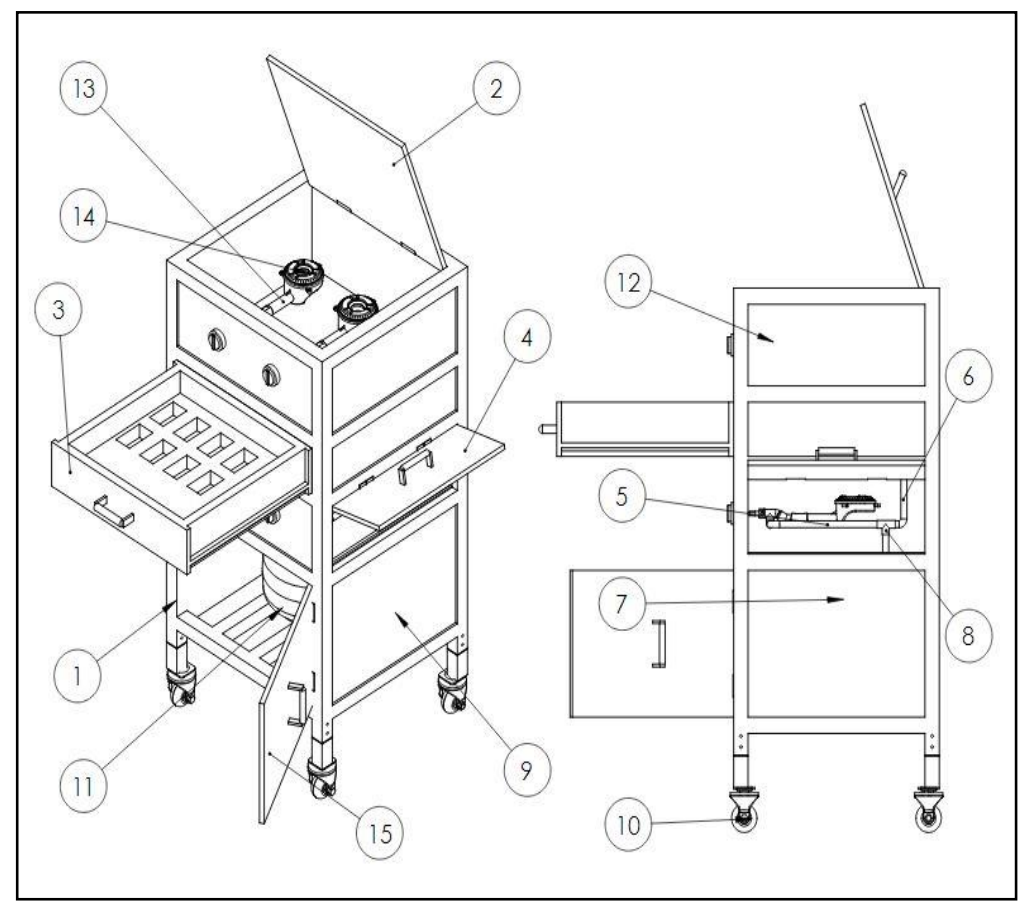

Gambar 11. Alat Panggang Kue Balok Rancangan 3 


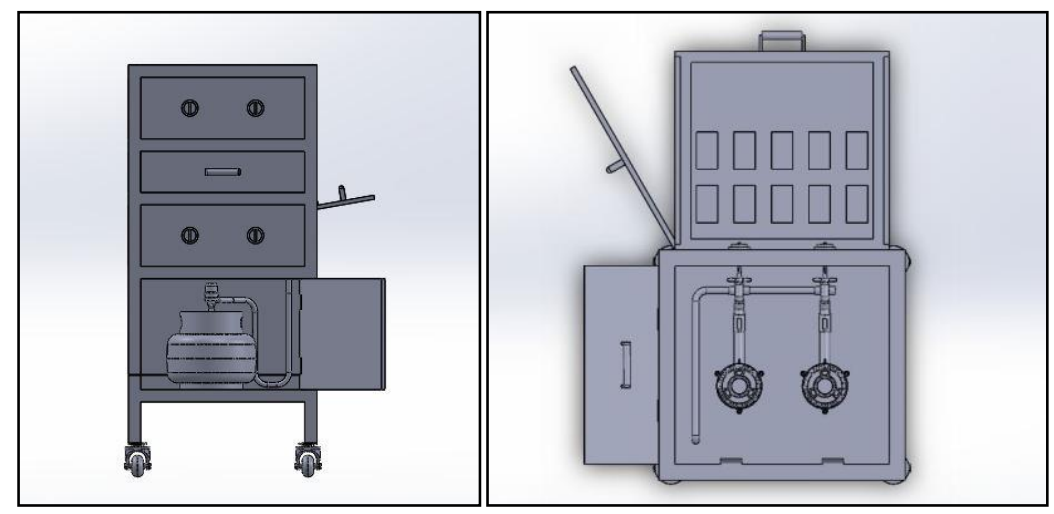

Gambar 12. Alat Panggang Kue Balok Rancangan 3 Tampak Depan dan Tampak Atas
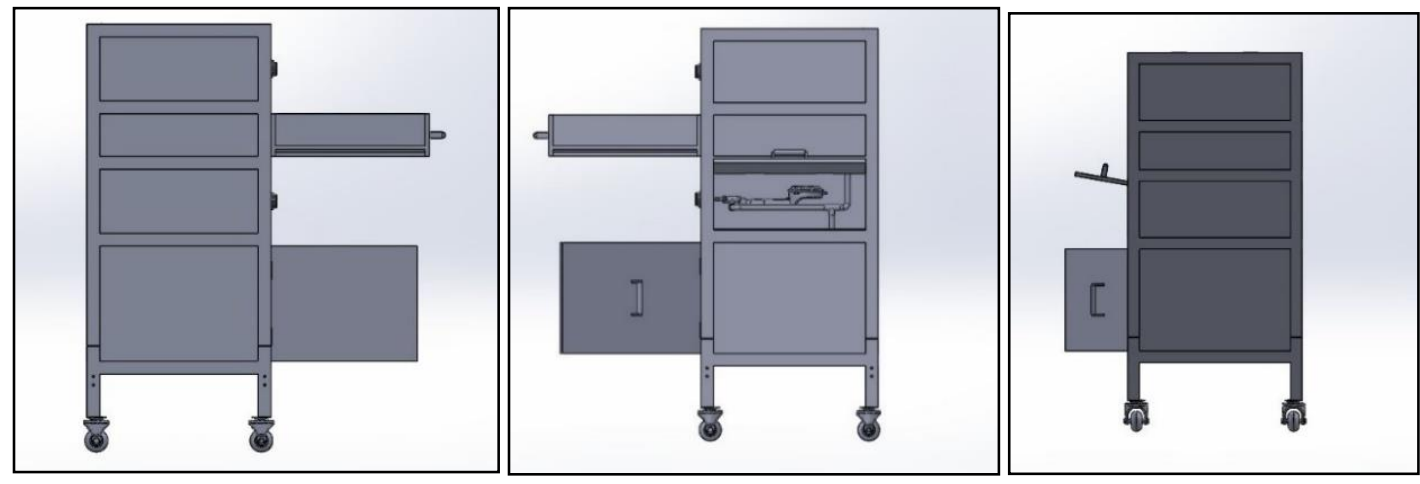

Gambar 13. Alat Panggang Kue Balok Rancangan 3 Tampak Samping Kiri, Tampak Samping Kanan, Tampak Belakang

Tabung gas diletakan didalam sebuah laci, sehingga alat panggang menjadi lebih rapih.

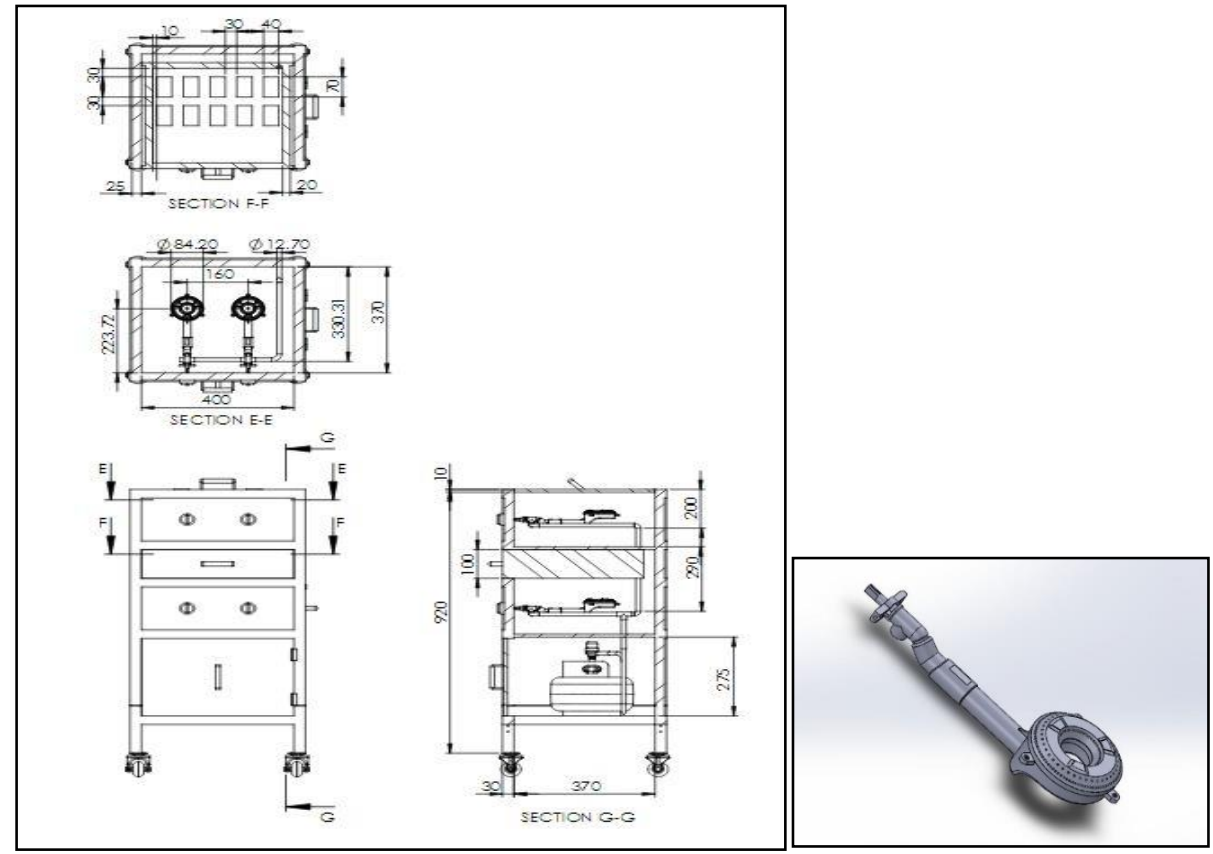

Gambar 14. Alat Panggang Kue Balok Rancangan 3 dan Tungku Bulat. 


\section{a. Kesimpulan}

\section{KESIMPULAN DAN SARAN}

Terdapat tiga alternatif rancangan alat panggang Kue Balok ramah lingkungan karena berbahan bakar gas, yang belum dilakukan konfirmasi atribut alat yang dirancang ke end user dan belum diuji fungsikan, sehingga belum bisa di tentukan rancangan yang paling optimal

\section{b. Saran}

Sebaiknya dilakukan pembuatan prototype dan konfirmasi atribut produk ke pemakai alat atau end user serta uji fungsi untuk menentukan rancangan yang paling baik.

\section{DAFTAR PUSTAKA}

[1] Ulrich, Karl T. dan Eppinger, Staven D. 2001.Perancangan Dan Pengembangan Produk. Jakarta: Salemba Teknika.

[2] Journal.unpar.ac.id/index.php/jrsi/article/view/2212/1999-tahun 2016 Rancangan Blueprint Alat Cetak Kue Balok yang Ergonomis dengan Metode Ergonomic Function Deployment

[3] Damayanti., K.A, 2000. Ergomonomic Function Deployment Sebuah Pengembangan Dari Quality Function Deployment.Jurnal. Surabaya. Lab APK dan Ergonomi Universitas Kristen Petra.

[4] Novirani, Dwi dan Permata, Gita (2016), "Perancangan Prototype Alat Cetak Kue Balok yang Ergonomis menggunakan Metode Ergonomic Function Deployment (EFD)"

[5] Ullman, D.G. (2010), “ The Mechanical Design Process", Published by McGraw-Hill, A business unit of The McGraw-Hill Compnies, Inc., 1221 Avenue of the Americas, New York, NY 10020, Four Edition, pp81-91

[6] Budynas, RG. And J Keith Nisbett, J,K, (2006), “Shigley's Mechanical Engineering Design”, $8^{\text {th }}$ Edition in SI Units, The Mc Graw-Hill Companies, Inc. pp. 71-118.

[7] Khurmi, R.S, and Gupta, J.K.(2005), “AText Book of Machine Design”, Eurasia Publishing House, Ram Nagar, New Delhi, $14^{\text {th }}$ Revised Edition, pp.281-676.

[8] Lawrence Gyansah, Design, Construction and Modeling of a Mechanical Portable Barbecue Machine, globaljournals.org/GJRE_Volume12/5 (2012)

[9] Pahl, G., Beitz, W. (2010). VDIGuideline2222, Systematic approach to the development and design of technical system and products.Verein Deutscher Inginieure. Berlin: Beuth Verlag.

[10] Monica, Lenny (2016) Perancangan Pemanggang untuk Penjual Sate di Pujasera dan Festival Makanan. Undergraduate thesis ubaya, Surabaya 2016

[11] Callister, Jr. W.D. and Rethwish, D.G.(2010), "Material Science and Engineering-An Itroduction", Eighth Edition, Jphn Willey \&Son, Inc. River Street, Hoboken, NJ. Pp. 1-800

[12] Craig, JR, R.R (2011), "Mechanics of Material", John Wiley \& Sons, Inc., USA, Third Edition, pp. $22-61$

[13] Harsokoesoemo, H. Darmawan (2004). Pengantar Perancangan Teknik (Perancangan Produk). Edisi Kedua. Bandung: Penerbit ITB.

[14] Ashby, M., Shercliff, H. and Cebon, D (2007), "Materials, Engineering, Science, Processing and Design”, Published by Elsevier Ltd., UK, pp. 1-500.

[15] Askeland, D.R., Fulay, P.P., and Wright, W.J. (2010), "The Science and Engineering of Mterials", Cengage Learning, 200 First Stamford Place, Suite 400, Stamford, CT 06902, USA, Sixth Edition, pp 1-900.

[16] Omura, G (2010), "Mastering AutoCAD 2011 and AutoCad LT 201" Wiley Publishing, Inc., Indianapolis, Indians, pp. 4-911 